DOI : 10.6564/JKMRS.2011.15.1.040

\title{
Nuclear Magnetic Resonance Study of the Raman Spin-Phonon Processes in the Relaxation Mechanisms of Double Sulfate $\mathrm{Li}_{3} \mathrm{Rb}\left(\mathrm{SO}_{4}\right)_{2}$ Single Crystals
}

\author{
Cheol Heo, ${ }^{1}$ Ae Ran Lim $^{2, *}$ \\ ${ }^{1}$ School of Energy and Integrated Materials Engineering, Kumoh National Institute of Technology, Gumi 730- \\ 701, Korea \\ ${ }^{2}$ Department of Science Education, Jeonju University, Jeonju 560-759, Korea \\ (Received May 01, 2011; accepted May 27, 2011)
}

\begin{abstract}
The NMR spectra of $\mathrm{Li}_{3} \mathrm{Rb}\left(\mathrm{SO}_{4}\right)_{2}$ crystals and their relaxation processes were investigated by using ${ }^{7} \mathrm{Li}$ and ${ }^{87} \mathrm{Rb}$ NMR. The relaxation rates of the ${ }^{7} \mathrm{Li}$ and ${ }^{87} \mathrm{Rb}$ nuclei in the crystals were found to increase with increasing temperature, and can be described by the relation $\mathrm{T}_{1}{ }^{-1} \propto \mathrm{AT}^{2}$. The dominant relaxation mechanism for these nuclei with electric quadrupole moments is provided by the coupling of these moments to the thermal fluctuations of the local electric field gradient via Raman spin-phonon processes.
\end{abstract}

Keywords: $\mathrm{Li}_{3} \mathrm{Rb}\left(\mathrm{SO}_{4}\right)_{2}$, spin-lattice relaxation time, phase transition temperature

\section{INTRODUCTION}

The increase in the number of studies of the physical properties of $\mathrm{LiASO}_{4}(\mathrm{~A}=\mathrm{K}, \mathrm{Rb}$, Cs, and $\mathrm{NH}_{4}$ ) single crystals is largely because of their excellent optical properties [1-5]. Double lithium

\footnotetext{
* To whom correspondence should be addressed. E-mail : aeranlim@hanmail.net
} 
rubidium sulfate, $\mathrm{Li}_{3} \mathrm{Rb}\left(\mathrm{SO}_{4}\right)_{2}$, has a monoclinic structure with one molecular formula unit per unit cell. The space group is $P 1$ and the lattice parameters of the monoclinic cell are a=5.1356 $\AA$, $\mathrm{b}=4.9853 \AA, \mathrm{c}=8.2712 \AA \mathrm{\alpha}=90.032^{\circ}, \beta=105.729^{\circ}$, and $\gamma=90.004^{\circ}$ at room temperature [6]. The lithium atoms are four-fold coordinated by oxygen atoms, with LiO distances in the range 1.890 $1.995 \AA$. In the cases of $\operatorname{Li}(1)$ and $\operatorname{Li}(2)$, the four oxygen atoms of the coordinated polyhedra belong to sulfate groups, whereas for $\operatorname{Li}(3)$ the tetrahedral coordination is defined by three oxygen atoms belonging to sulfate groups. The rubidium atoms lie approximately at the centers of the large cavities in this tetrahedral framework. The $\mathrm{SO}_{4}{ }^{2-}$ anion is an almost regular tetrahedron, with $\mathrm{S}-\mathrm{O}$ distances ranging from $1.466 \AA$ to $1.485 \AA$. Each $\mathrm{SO}_{4}$ tetrahedron shares all of its corners with distorted $\mathrm{LiO}_{4}$ tetrahedra. The $\mathrm{SO}_{4}$ and $\mathrm{LiO}_{4}$ tetrahedra linkage pattern is similar to that found in other related lithium sulfates that exhibit tridymite-like structures [6]. Figure 1 shows the projection of the $\mathrm{Li}_{3} \mathrm{Rb}\left(\mathrm{SO}_{4}\right)_{2}$ structure along [010]. Although the growth and characterization for $\mathrm{Li}_{3} \mathrm{Rb}\left(\mathrm{SO}_{4}\right) \cdot \mathrm{H}_{2} \mathrm{O}$ have been reported by Pina [6], sufficient research has not yet been conducted into the physical properties.

The spin-lattice relaxation rates of a crystal's nuclei reflect its dynamics, such as its nucleusphonon interactions, and indicate how easily the excited state energy of the nuclear system is transferred into the lattice. In order to obtain detailed information about the dynamics of $\mathrm{Li}_{3} \mathrm{Rb}\left(\mathrm{SO}_{4}\right)_{2}$ crystals, it is useful to measure the spin-lattice relaxation rates, $\mathrm{T}_{1}{ }^{-1}$, of their constituent ${ }^{7} \mathrm{Li}$ and ${ }^{87} \mathrm{Rb}$ nuclei. In the present study, $\mathrm{Li}_{3} \mathrm{Rb}\left(\mathrm{SO}_{4}\right)_{2}$ crystals were grown by using the slow evaporation of 
42 Nuclear Magnetic Resonance Study of Double Sulfate $\mathrm{Li}_{3} \mathrm{Rb}\left(\mathrm{SO}_{4}\right)_{2}$ Single Crystals

aqueous solutions. The lattice constants and the phase transition temperature of this crystal were determined by using X-ray diffraction and differential scanning calorimetry (DSC) respectively. To probe the structural properties of this crystal, the measurement of the ${ }^{7} \mathrm{Li}$ and ${ }^{87} \mathrm{Rb}$ relaxation rates was preferred, because these relaxation rates are likely to be very sensitive to changes in its symmetry. The nuclear magnetic resonance (NMR) spectra and spin-lattice relaxation rates, $\mathrm{T}_{1}^{-1}$, for ${ }^{7} \mathrm{Li}$ and ${ }^{87} \mathrm{Rb}$ in $\mathrm{Li}_{3} \mathrm{Rb}\left(\mathrm{SO}_{4}\right)_{2}$ single crystals were obtained. The present study examined the influence of nucleus-phonon interactions on the ${ }^{7} \mathrm{Li}$ and ${ }^{87} \mathrm{Rb}$ nuclei.

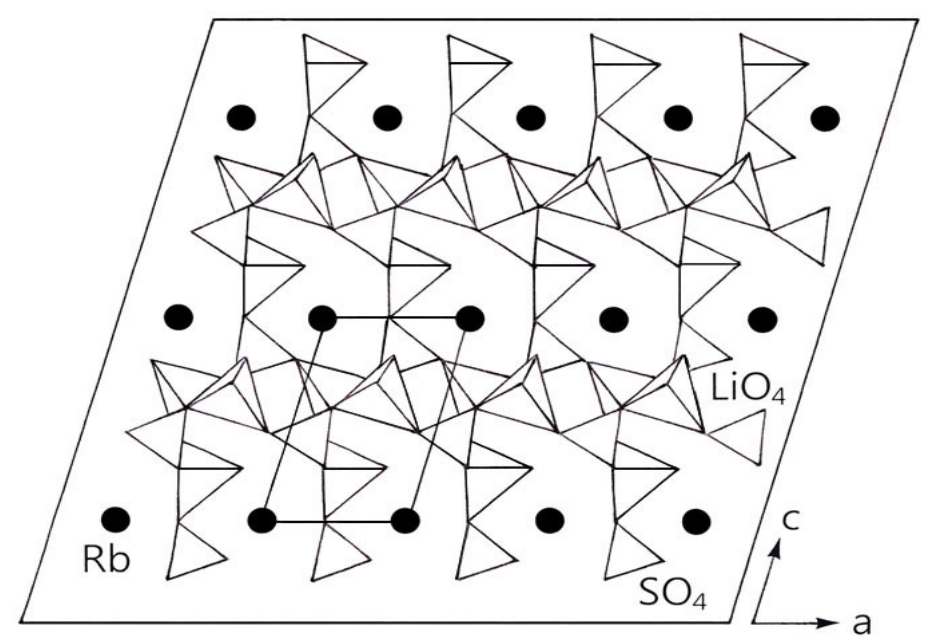

Figure. 1. Crystal structure of $\mathrm{Li}_{3} \mathrm{Rb}\left(\mathrm{SO}_{4}\right)_{2}$ projected along [010]. 


\section{EXPERIMENTAL}

$\mathrm{Li}_{3} \mathrm{Rb}\left(\mathrm{SO}_{4}\right)_{2}$ mixed crystals were obtained by slow evaporation of aqueous solutions of $\mathrm{Li}_{2} \mathrm{SO}_{4}$ and $\mathrm{Rb}_{2} \mathrm{SO}_{4}$ in the appropriate molar ratios at room temperature. The crystals were transparent and colorless. The lattice constants of the $\mathrm{Li}_{3} \mathrm{Rb}\left(\mathrm{SO}_{4}\right)_{2}$ single crystals at room temperature were determined with an X-ray diffractometer system (Bruker AXS GMBH) at the Korea Basic Science Institute. The $\mathrm{Li}_{3} \mathrm{Rb}\left(\mathrm{SO}_{4}\right)_{2}$ crystal has a triclinic structure with cell parameters $\mathrm{a}=5.1415 \AA, \mathrm{b}=4.9872$ $\AA, \mathrm{c}=8.2776 \AA \AA \mathrm{\alpha}=90.041^{\circ}, \beta=105.838^{\circ}$, and $\gamma=89.990^{\circ}$ at room temperature. These results are consistent with those of Pina et al. [6]. The phase transition temperature was determined by using a DuPont 2010 DSC instrument. The measurements were performed at a heating rate of $10 \mathrm{~K} / \mathrm{min}$. The phase transition of $\mathrm{Li}_{3} \mathrm{Rb}\left(\mathrm{SO}_{4}\right)_{2}$ was found to occur at $468 \mathrm{~K}$, as shown in Fig. 2. The NMR spectra and the spin-lattice relaxation rates of the ${ }^{7} \mathrm{Li}$ and ${ }^{87} \mathrm{Rb}$ nuclei in the $\mathrm{Li}_{3} \mathrm{Rb}\left(\mathrm{SO}_{4}\right)_{2}$ single crystals were measured by using the Bruker DSX 400 FT NMR spectrometers at the Korea Basic Science Institute. The static magnetic field was $9.4 \mathrm{~T}$, and the central radio frequency was set at $\omega_{\mathrm{L}} / 2 \pi=155.51 \mathrm{MHz}$ for the ${ }^{7} \mathrm{Li}$ nucleus and at $\omega_{\mathrm{Rb}} / 2 \pi=130.92 \mathrm{MHz}$ for the ${ }^{87} \mathrm{Rb}$ nucleus. The spin-lattice relaxation rates for the ${ }^{7} \mathrm{Li}$ and ${ }^{87} \mathrm{Rb}$ nuclei were measured by applying the pulse sequences $\pi+2 t-\pi / 2$ and $\pi-t-\pi / 2$ respectively. The nuclear magnetizations $\mathrm{M}(t)$ of the ${ }^{7} \mathrm{Li}$ and ${ }^{87} \mathrm{Rb}$ nuclei at time $t$ after the $\pi / 2$ and $\pi$ pulses were determined from the saturation and inversion recovery sequence following each pulse. The width of the $\pi / 2$ pulse for ${ }^{7} \mathrm{Li}$ was $5 \mu$ s and the width of the $\pi$ pulse for ${ }^{87} \mathrm{Rb}$ was $1.65 \mu$ s. The temperature dependences of the NMR measurements were obtained in the temperature range 160-410 
44 Nuclear Magnetic Resonance Study of Double Sulfate $\mathrm{Li}_{3} \mathrm{Rb}\left(\mathrm{SO}_{4}\right)_{2}$ Single Crystals

K. Unfortunately, the relaxation rates could not be determined above $420 \mathrm{~K}$ because the NMR spectrometer did not have adequate temperature control at higher temperatures. The temperature of each sample was held constant by controlling the nitrogen gas flow and heater current, giving an accuracy of $\pm 0.5^{\circ} \mathrm{C}$.

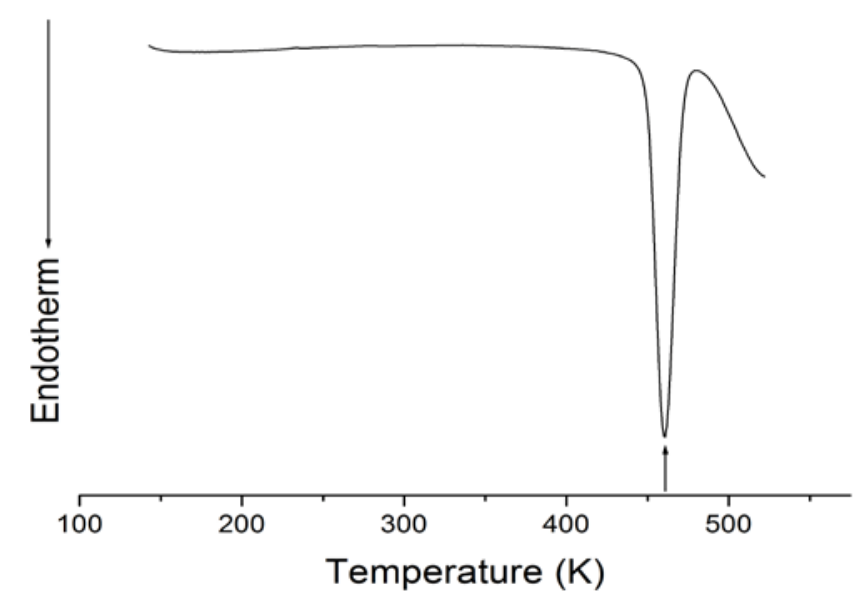

Figure. 2. Differential scanning calorimetry (DSC) thermogram for $\mathrm{Li}_{3} \mathrm{Rb}\left(\mathrm{SO}_{4}\right)_{2}$.

\section{RESULTS AND DISCUSSION}

We now describe the recovery laws for the quadrupole relaxation processes of the ${ }^{7} \mathrm{Li}(\mathrm{I}=3 / 2)$ and ${ }^{87} \mathrm{Rb}(\mathrm{I}=3 / 2)$ nuclei in the $\mathrm{Li}_{3} \mathrm{Rb}\left(\mathrm{SO}_{4}\right)_{2}$ single crystals. The transition probabilities for $\Delta \mathrm{m}= \pm 1$ and $\Delta \mathrm{m}= \pm 2$ are denoted $W_{1}$ and $W_{2}$ respectively. The inversion recovery function for the central resonance line is [7-11] 


$$
\mathrm{M}(\infty)-\mathrm{M}(t) / 2 \mathrm{M}(\infty)=0.5\left[\exp \left(-2 W_{1} t\right)+\exp \left(-2 W_{2} t\right)\right]
$$

where $\mathrm{M}(t)$ is the nuclear magnetization corresponding to the central transition at time $t$ after saturation.

The NMR spectrum of ${ }^{7} \mathrm{Li}(\mathrm{I}=3 / 2)$ in $\mathrm{Li}_{3} \mathrm{Rb}\left(\mathrm{SO}_{4}\right)_{2}$ was obtained at a frequency of $\omega_{0} / 2 \pi=155.51$ MHz. When such crystals are rotated about the crystallographic axis, the crystallographically equivalent nuclei are expected to give rise to three lines: one central line and two satellite lines. However, the ${ }^{7} \mathrm{Li}$ NMR spectrum consists of two groups of resonance lines when the magnetic field is applied to the crystal along an arbitrary direction, as shown in Fig. 3(a). The spectral features point to the presence of two types of crystallographically inequivalent ${ }^{7} \mathrm{Li}$ nuclei in the crystal structure. $\mathrm{Li}(1)$ and $\operatorname{Li}(2)$ are equivalent, but are not equivalent to $\mathrm{Li}(3)$, as is consistent with previous reports [6]. The ${ }^{7} \mathrm{Li}$ NMR signal intensities of $\mathrm{Li}(1), \operatorname{Li}(2)$, and $\mathrm{Li}(3)$ do not enable them to be distinguished, and the central resonance lines of the two groups overlap. As shown in Fig. 3(a), the satellite transitions are well resolved from the central resonance line, and the central line has the strongest signal intensity. The central transition is virtually unshifted by the quadrupole interaction. The spacing between the resonance lines decreases with increasing temperature for one group $(\circ)$, and is nearly constant with increasing temperature for the other group).(The temperature dependence of the splitting of the ${ }^{7} \mathrm{Li}$ resonance lines indicates a change with temperature in the electric field gradient 
46 Nuclear Magnetic Resonance Study of Double Sulfate $\mathrm{Li}_{3} \mathrm{Rb}\left(\mathrm{SO}_{4}\right)_{2}$ Single Crystals

(EFG) at the Li sites, which in turn means that the atoms neighboring the ${ }^{7} \mathrm{Li}$ nuclei change their configuration.

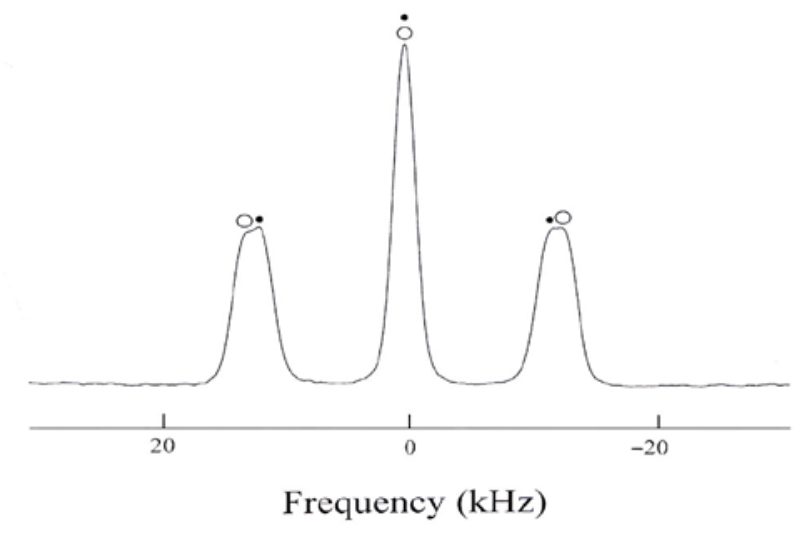

Figure. 3. (a) NMR spectrum for ${ }^{7} \mathrm{Li}$ in $\mathrm{Li}_{3} \mathrm{Rb}\left(\mathrm{SO}_{4}\right)_{2}$ crystals at room temperature,

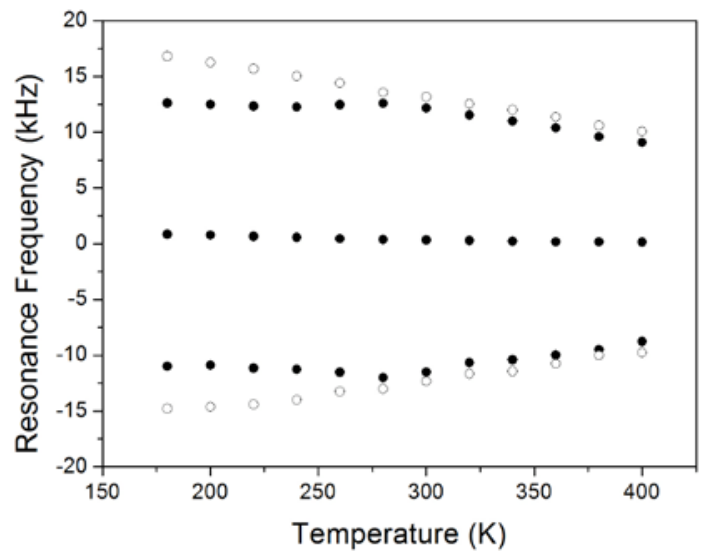

Figure. 3. (b) the splitting of the resonance lines for the $\mathrm{Li}$ nuclei in a $\mathrm{Li}_{3} \mathrm{Rb}\left(\mathrm{SO}_{4}\right)_{2}$ single crystal as a function of temperature. 
The temperature dependence of the relaxation rate of the central resonance line for Li was measured. The recovery traces for the central resonance line of $\mathrm{Li}_{3} \mathrm{Rb}\left(\mathrm{SO}_{4}\right)_{2}$ can be represented by the combination of two exponential functions in Eq. (1). The spin-lattice relaxation rate $\mathrm{T}_{1}{ }^{-1}$ for ${ }^{7} \mathrm{Li}$ was obtained in terms of $W_{1}$ and $W_{2}$, and can be represented by a single exponential relaxation function when $W_{1}=W_{2}$. The temperature dependence of the ${ }^{7} \mathrm{Li}$ spin-lattice relaxation rate of $\mathrm{Li}_{3} \mathrm{Rb}\left(\mathrm{SO}_{4}\right)_{2}$ is shown in Fig. 4. The spin-lattice relaxation rate $\mathrm{T}_{1}^{-1}$ for ${ }^{7} \mathrm{Li}$ increases monotonically with temperature. The $\mathrm{T}_{1}^{-1}$ value is short because the electric quadrupole moment is very small; the spin-lattice relaxation rate $\mathrm{T}_{1}^{-1}$ is proportional to the electric quadrupole moment, $\left.\mathrm{Q}, \mathrm{T}_{1}^{-1} \propto\left(\mathrm{e}^{2} \mathrm{qQ} / \mathrm{h}\right)^{2}\right][12]$. The relaxation rate for the ${ }^{7} \mathrm{Li}$ nuclei increases with increasing temperature, and can be fitted with the equation $\mathrm{T}_{1}^{-1}=\mathrm{AT}^{2}+\mathrm{B}$, shown as the solid curve in Fig. 4. The temperature dependence of the relaxation time follows a simple Arrhenius expression, $T_{1}=A \exp \left(E_{a} / R T\right)$. The activation energy for the $\mathrm{Li}-\mathrm{O}$ molecular motion can be obtained from the appropriate portion of the $\log \mathrm{T}_{1}$ versus $1000 / \mathrm{T}$ curve and was found to be $5.06 \mathrm{~kJ} / \mathrm{mol}$. 
48 Nuclear Magnetic Resonance Study of Double Sulfate $\mathrm{Li}_{3} \mathrm{Rb}\left(\mathrm{SO}_{4}\right)_{2}$ Single Crystals

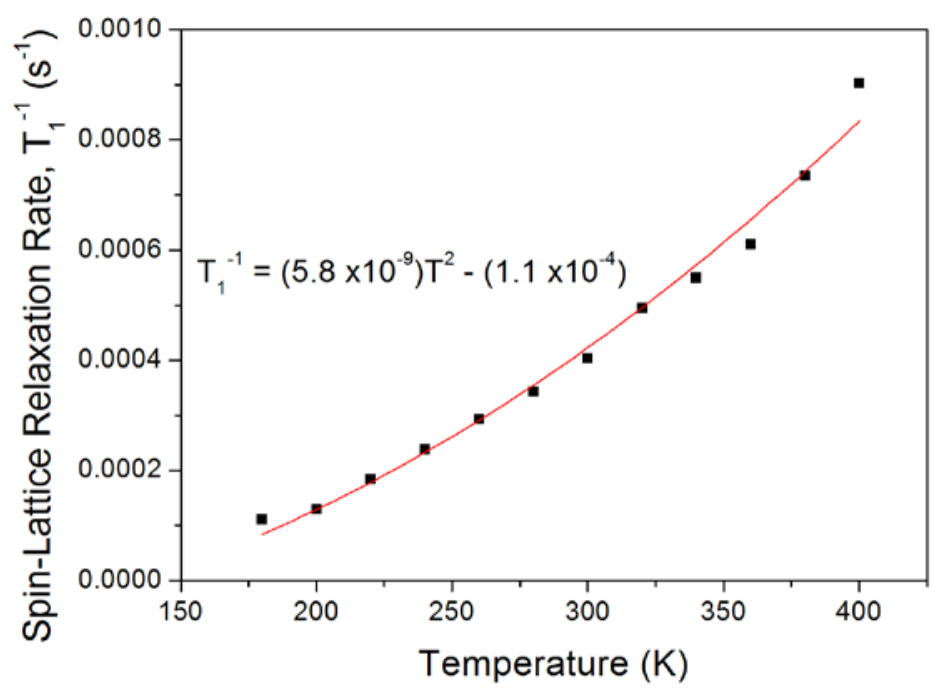

Figure. 4. Temperature dependence of the spin-lattice relaxation rate, $\mathrm{T}_{1}^{-1}$, for ${ }^{7} \mathrm{Li}$ in a $\mathrm{Li}_{3} \mathrm{Rb}\left(\mathrm{SO}_{4}\right)_{2}$ crystal. The solid curve is a fit with the function $\mathrm{T}_{1}^{-1}=\mathrm{AT}^{n}+\mathrm{B}$.

The ${ }^{87} \mathrm{Rb}(\mathrm{I}=3 / 2)$ NMR spectrum consists of a pair of satellite lines and a central line. As a result of the quadrupole interaction of the ${ }^{87} \mathrm{Rb}$ nucleus, three resonance lines are expected. The magnitudes of the quadrupole parameters of ${ }^{87} \mathrm{Rb}$ nuclei are of the order of $\mathrm{MHz}$, so usually the ${ }^{87} \mathrm{Rb}$ central line is affected by second-order quadrupolar shift [12]. Thus, the separation of the three resonance lines is not equivalent, as shown in Fig. 5. 


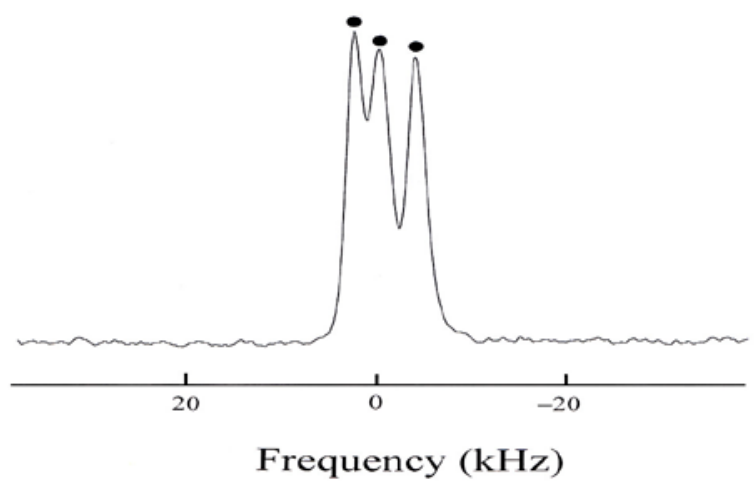

Figure. 5. NMR spectrum for ${ }^{87} \mathrm{Rb}$ in $\mathrm{Li}_{3} \mathrm{Rb}\left(\mathrm{SO}_{4}\right)_{2}$ crystals at room temperature.

The spin-lattice relaxation rates of ${ }^{87} \mathrm{Rb}$ in $\mathrm{Li}_{3} \mathrm{Rb}\left(\mathrm{SO}_{4}\right)_{2}$ were determined by examining the recovery traces of the magnetization of the ${ }^{87} \mathrm{Rb}$ nucleus at several different temperatures. The inversion recovery curves obtained at $200 \mathrm{~K}, 300 \mathrm{~K}$, and $400 \mathrm{~K}$ are shown in Fig. 6. The recovery trace for the central line of ${ }^{87} \mathrm{Rb}$ with dominant quadrupole relaxation can be represented by the combination of two exponential functions in Eq. (1). $W_{1}$ is nearly equal to $W_{2}$ over the whole temperature range. If $W_{1}$ and $W_{2}$ have the same values in the recovery traces of ${ }^{87} \mathrm{Rb}$ in $\mathrm{Li}_{3} \mathrm{Rb}\left(\mathrm{SO}_{4}\right)_{2}$ crystals, we can define a relaxation rate $T_{1}^{-1}$ according to $\mathrm{T}_{1}^{-1}=2 W_{1}$. When $W_{1} \neq W_{2}$, the constant $\left[2\left(\mathrm{~W}_{1}+4 \mathrm{~W}_{2}\right)\right] / 5$ is introduced instead of $\mathrm{T}_{1}^{-1}$; this constant is identical to $\mathrm{T}_{1}^{-1}$ when $W_{1}=W_{2}$. The relaxation rates were obtained by combining the transition probabilities $W_{1}$ and $W_{2}$ according to Eq. (1), and the spin-lattice relaxation rate $\mathrm{T}_{1}{ }^{-1}$ was obtained as shown in Fig. 7. The relaxation rates for the ${ }^{87} \mathrm{Rb}$ nuclei increase with increasing temperature. The relaxation rates for the three resonance 
50 Nuclear Magnetic Resonance Study of Double Sulfate $\mathrm{Li}_{3} \mathrm{Rb}\left(\mathrm{SO}_{4}\right)_{2}$ Single Crystals

signals are consistent within experimental error: the ${ }^{87} \mathrm{Rb}$ relaxation times are short, $279 \mathrm{~ms}$ at $200 \mathrm{~K}$ and $121 \mathrm{~ms}$ at $300 \mathrm{~K}$. The spin-lattice relaxation time is $\mathrm{T}_{1}=95 \mathrm{~ms}$ at $300 \mathrm{~K}$. The spin-lattice relaxation rate, $\mathrm{T}_{1}{ }^{-1}$, for ${ }^{87} \mathrm{Rb}$ in this single crystal increases with temperature, as shown in Fig. 7 . The relaxation rate of the ${ }^{87} \mathrm{Rb}$ nuclei undergoes no abrupt changes within the temperature range 180-400 $\mathrm{K}$, which indicates that no phase transitions occur within this temperature range. The activation energy for the $\mathrm{Rb}-\mathrm{O}$ molecular motion was found to be $5.20 \mathrm{~kJ} / \mathrm{mol}$.

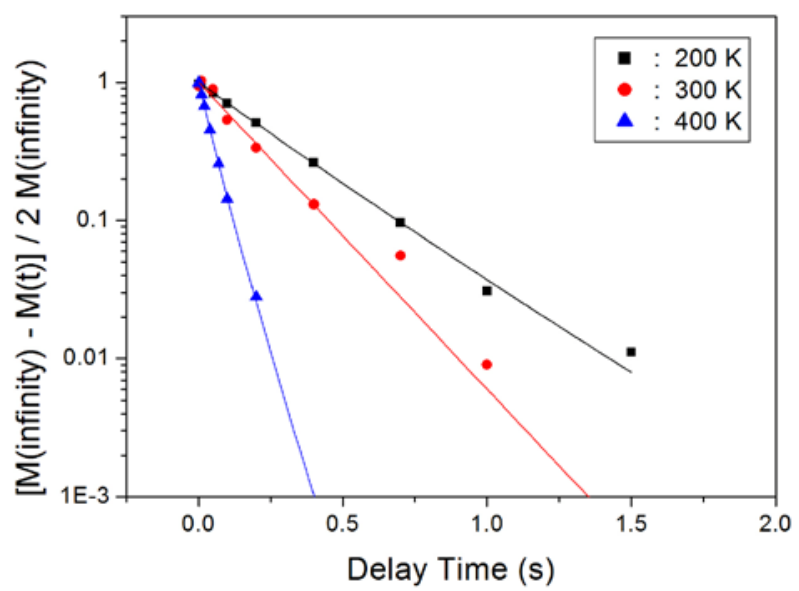

Figure. 6. The inversion recovery traces of ${ }^{87} \mathrm{Rb}$ as functions of the delay time at $200 \mathrm{~K}, 300 \mathrm{~K}$, and $400 \mathrm{~K}$.

According to our experimental results, the temperature dependences of $\mathrm{T}_{1}^{-1}$ in $\mathrm{Li}_{3} \mathrm{Rb}\left(\mathrm{SO}_{4}\right)_{2}$ can be described by the approximations $\mathrm{T}_{1}^{-1}=\left(5.8 \times 10^{-9}\right) \mathrm{T}^{2}-\left(1.1 \times 10^{-4}\right)$ for the ${ }^{7} \mathrm{Li}$ nucleus and 
$\mathrm{T}_{1}^{-1}=\left(1.3 \times 10^{-4}\right) \mathrm{T}^{2}-2.5$ for the ${ }^{87} \mathrm{Rb}$ nucleus, as shown by the solid curves in Figs. 4 and 7 . These temperature dependences of the ${ }^{7} \mathrm{Li}$ and ${ }^{87} \mathrm{Rb}$ relaxation rates of $\mathrm{Li}_{3} \mathrm{Rb}\left(\mathrm{SO}_{4}\right)_{2}$ are in accordance with Raman processes, which scale with $\mathrm{T}^{2}$. Thus, in all of the cases considered, Raman processes scaling with $\mathrm{T}^{2}$ are more effective in nuclear quadrupole relaxation than direct processes. The behavior of $\mathrm{T}_{1}^{-1}$ in this system can be explained in terms of a relaxation mechanism in which the lattice vibrations are coupled to the nuclear electric quadrupole moments.

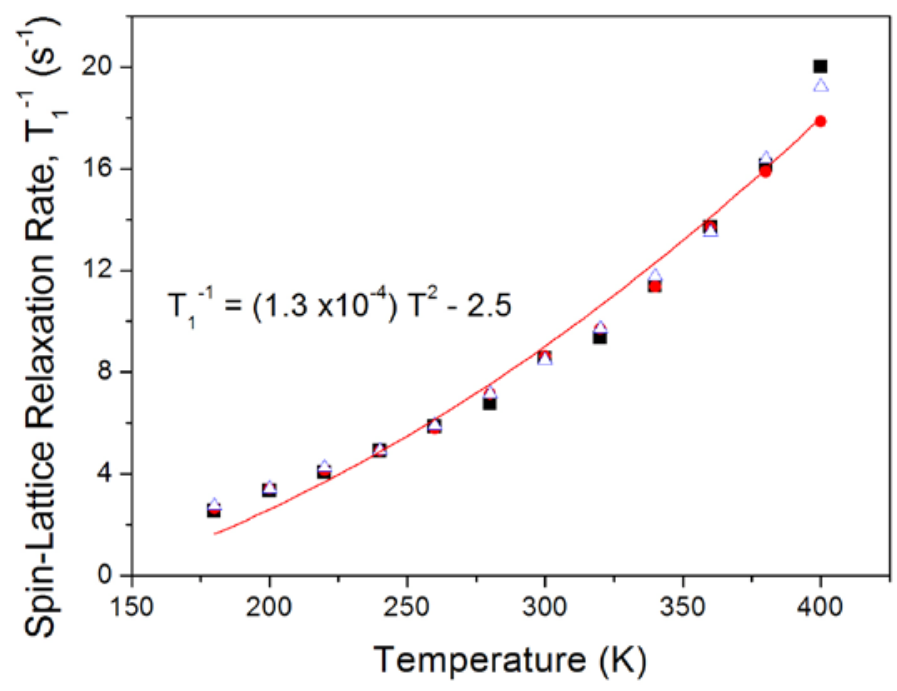

Figure. 7. Temperature dependences of the spin-lattice relaxation rate, $\mathrm{T}_{1}{ }^{-1}$, for ${ }^{87} \mathrm{Rb}$ in a $\mathrm{Li}_{3} \mathrm{Rb}\left(\mathrm{SO}_{4}\right)_{2}$ crystal. The solid curve is a fit with the function $\mathrm{T}_{1}^{-1}=\mathrm{AT}^{n}+\mathrm{B}$. 


\section{CONCLUSION}

$\mathrm{Li}_{3} \mathrm{Rb}\left(\mathrm{SO}_{4}\right)_{2}$ single crystals were grown by using the slow evaporation method, and their lattice constants were determined with X-ray diffraction. We investigated the structural properties and phase transition properties of the $\mathrm{Li}_{3} \mathrm{Rb}\left(\mathrm{SO}_{4}\right)_{2}$ crystal by means of ${ }^{7} \mathrm{Li}$ and ${ }^{87} \mathrm{Rb} \mathrm{NMR}$ relaxation and DSC. Further, the differences between the $\mathrm{T}_{1}^{-1}$ values of the two nuclei can be attributed to their different Larmor and quadrupole frequencies, amongst other factors. The electric quadrupole moments of Li and $\mathrm{Rb}$ are $\mathrm{Q}_{\mathrm{Li}}=-4.0 \times 10^{-30} \mathrm{~m}^{2}$ and $\mathrm{Q}_{\mathrm{Rb}}=13 \times 10^{-30} \mathrm{~m}^{2}$ respectively and the spin-lattice relaxation rate is proportional to the square of the quadrupole coupling constant [9, 12].

The dominant relaxation mechanism for nuclei with electric quadrupole moments is the coupling of these moments to the thermal fluctuations of the local electric field gradients via Raman spinphonon processes. A theory of nuclear quadrupolar spin-lattice relaxation was first proposed by van Kranendonk [13, 14]. According to van Kranendonk [15], the contribution of a Raman process to the spin-lattice relaxation rate is given by $1 / \mathrm{T}_{1}=\left(\mathrm{T}^{*}\right)^{2} f\left(\mathrm{~T}^{*}\right)$, where $\mathrm{T}^{*}$ is the reduced temperature $\mathrm{T}^{*}=\mathrm{T} / \theta$ ( $\theta$ is the Debye temperature). The function $f\left(T^{*}\right)$ is proportional to $\left(T^{*}\right)^{5}$ in the low temperature limit, $\mathrm{T}^{*}<<0.02$, but is constant in the high-temperature limit, $\mathrm{T}^{*}>0.5$ [15]. The relaxation rates for ${ }^{7} \mathrm{Li}$ and

${ }^{87} \mathrm{Rb}$ increase with increasing temperature and can be described with $\mathrm{T}_{1}^{-1} \propto \mathrm{AT}^{2}$. The $\mathrm{T}_{1}^{-1}$ results for ${ }^{7} \mathrm{Li}$ and ${ }^{87} \mathrm{Rb}$ in $\mathrm{Li}_{3} \mathrm{Rb}\left(\mathrm{SO}_{4}\right)_{2}$ crystals can thus be explained in terms of a relaxation mechanism in which the lattice vibrations are coupled to the nuclear electric quadrupole moments. 


\section{Acknowledgement}

This study was supported by the Mid-Career Researcher Program through an NRF grant funded by the MEST (No. 2011-0000107).

\section{REFERENCES}

1. O. V. Bovgyra, I. Stadnyk, and O. Z. Chyzh, Phys. Solid State 48, 1268. (2006).

2. M. Maghrabi, A. A. Finch, and P. D. Townsend, J. Phys. Condensed Matter 20, 455207. (2008).

3. A. R. Lim, P. H. Bong, S. Y. Jeong, and S. H. Kim, J. Phys. Soc. Japan 78, 104701. (2009).

4. D. MacHon, C. B. Pinheiro, P. Bouvier, V. P. Dmitriev, and W. A. Crichton, J. Phys. Condensed Matter 22, 315401. (2010).

5. Z. Tylczynski, Central European J. Phys. 9, 722. (2011).

6. C. M. Pina, L. F. Diaz, E. Molins, R. M. Rojas, J. M. Rojo, Z. Kristallogr. 213, 635. (1998).

7. M. Igarashi, H. Kitagawa, S. Takahashi, R. Yoshizak, Y. Abe, and Z. Naturforsch, A: Phys. Sci. 47, 313. (1992).

8. J. J. Van der Klink, D. Rytz, F. Borsa, and U. T. Hochli, Phys. Rev. B 27, 89. (1983).

9. A. R. Lim, S. Y. Jeong, and S. H. Kim, J. Appl. Phys. 108, 114101. (2010).

10. K. S. Han, and M. Lee, J. Kor. Magn. Reson. 13, 135. (2009).

11. A. R. Lim, and W. K. Jung, J. Kor. Magn. Reson. 14, 18. (2010).

12. A. Abragam, “ The Principles of Nuclear Magnetism” Oxford University Press, Oxford, (1961).

13. J. van Kranendonk, and M. B. Walker, Phys. Rev. Letter 18, 701. (1967).

14. J. van Kranendonk, Physica B 20, 781. (1954).

15. J. van Kranendonk, Can. J. Phys. 46, 2441. (1968). 